\title{
The effect of caffeine on postprandial blood pressure in the frail elderly
}

\author{
D. Heseltine, M. El-Jabri, F. Ahmed and J. Knox
}

Department of Medicine for the Elderly, Kingston General Hospital, Beverley Road, Hull HU3 IUR, UK

Summary: In a double-blind, random-order, cross-over study the effects of placebo and $100 \mathrm{mg}$ of caffeine on postprandial sitting and erect blood pressure and heart rate were studied in 20 frail elderly subjects (mean age 84, range 75-93 years) after a standardized $400 \mathrm{~K}$-calorie glucose drink. Maximal postprandial reduction in sitting systolic blood pressure occurred, at 60 minutes post-placebo, of $-11 \mathrm{mmHg}(95 \%$ confidence interval -5 to $-17 \mathrm{mmHg}, P<0.01)$, and was attenuated by caffeine $(P<0.05)$ with changes in systolic blood pressure, at 60 minutes post-drink, of $1 \mathrm{mmHg}(95 \% \mathrm{CI}-6$ to $7 \mathrm{mmHg}$, not significant). Four subjects developed symptomatic postprandial hypotension after placebo which was prevented by caffeine. There were no significant changes in erect systolic blood pressure, postural systolic blood pressure change, sitting and erect, diastolic blood pressure and heart rate between treatment phases.

Caffeine attenuates the postprandial fall in sitting blood pressure in frail elderly subjects and in particular prevented symptomatic blood pressure reductions in subjects with postprandial hypotension.

\section{Introduction}

Postprandial falls in blood pressure occur in elderly subjects after a meal, ${ }^{1,2}$ the greatest changes occurring after a high carbohydrate intake, ${ }^{3}$ and in frail, very old subjects. ${ }^{4}$ The mechanisms by which changes occur are poorly understood but may be related to increased splanchnic and peripheral blood flow mediated by insulin, vaso-active gastrointestinal hormones, ${ }^{5}$ or adenosine. ${ }^{6}$

Caffeine is a pressor agent and is known to increase blood pressure in the elderly ${ }^{7}$ possibly by stimulation of the sympathetic nervous system, ${ }^{8}$ renin angiotensin system, ${ }^{9}$ or by blocking vasodilatory adenosine receptors. ${ }^{10}$ In subjects with autonomic failure, caffeine pre-treatment prevented postprandial hypotension. ${ }^{11}$ However, in healthy elderly subjects conflicting results have been observed on the effects of caffeine on postprandial blood pressure changes. Caffeine given 60 minutes before food failed to prevent the postprandial fall in blood pressure, ${ }^{12}$ but when given after food this fall was attenuated. ${ }^{13}$ This difference may be explained by the maximal pharmacological action of caffeine treatment post-meal occurring simultaneously with the maximal hypotensive effect of the meal. These studies have only been undertaken

Correspondence: D. Heseltine, MB, MRCP, York District Hospital, Wiggington Road, York YO3 7HE, UK.

Accepted: 21 December 1990 in fit elderly subjects and have only used 'supranormal' dosages of caffeine $(200-250 \mathrm{mg})$ equivalent to three to four cups of coffee. ${ }^{14}$

As syncope and other problems related to low blood pressure are more common in the frail elderly the present study was performed to evaluate the effects of a lower dose of caffeine $(100 \mathrm{mg}$ equivalent to one strong cup of coffee or tea $)^{14}$ on postprandial blood pressure changes in frail, very old subjects.

\section{Subjects and methods}

\section{Subjects}

Twenty subjects participated in the study [ 10 male, mean age $84 \pm 5$ (s.d.), range 75-93 years]. Two subjects described symptoms of postural hypotension, although no subjects had a postural fall in systolic blood pressure greater than $20 \mathrm{mmHg}$ recorded one minute after changing from a supine to erect position. A further two subjects described symptoms of light headedness and unsteadiness after ingesting a heavy meal. All subjects were completing a period of rehabilitation after acute admission to the Department of Medicine for the Elderly and were due to be discharged to their own home (15), residential or nursing home (5).

Subjects had a series of medical problems; cerebrovascular disease (4), ischaemic heart disease (3), 
peripheral vascular disease (2), congestive cardiac failure (4), chronic obstructive airways disease (4), osteoarthritis (5), diabetes mellitus (3) and Parkinson's disease (1). Medications prescribed were: loop diuretics (2), thiazide diuretics (1), angiotensin-converting enzyme inhibitor (1), calcium antagonists (2), digoxin (1), paracetamol (2), minor tranquillizers (1), L-dopa and decarboxylase inhibitor (1) and inhaled bronchodilators (3).

Subjects were selected according to the following criteria: they had recovered from their admission illness, had no mental deterioration and were able to stand and walk with or without the help of one person or an aid. All were accustomed to a mean daily intake of caffeine of $200 \pm 50 \mathrm{mg}$ (s.d.) ingested as coffee or tea (caffeine: instant coffee $65 \mathrm{mg}$ per cup, tea $45 \mathrm{mg}$ per cup).${ }^{14}$ All subjects gave informed consent and the study was approved by the Local Health District Ethical Committee.

\section{Methods}

Each subject was studied on two occasions on consecutive days. After overnight abstinence from alcohol, smoking, medication and caffeine, subjects were allowed a light breakfast at $0800 \mathrm{~h}$ and investigations were commenced at $1200 \mathrm{~h}$. The study was conducted at their bedside.

Throughout the study all subjects rested in a sitting position. Recordings were taken of blood pressure (BP) and heart rate (HR). Blood pressure was recorded using a Hawksley Random-zero sphygmomanometer (diastolic BP taken at Korotkoff phase $V$ ), the mean of two recordings being taken as the actual blood pressure both sitting and after one minute of standing. An electrocardiograph recorded heart rate sitting and erect over a period of 30 seconds. At $1230 \mathrm{~h}$ subjects consumed a standardized $400 \mathrm{~K}$-calorie glucose drink (Hycal) over 5 minutes, and, on completion, consumed either caffeinated coffee (Nescafe Blend 37), weighed to contain $100 \mathrm{mg}$ of caffeine, or decaffeinated coffee (Nescafe Gold Blend Decaffeinated) dissolved in $100 \mathrm{ml}$ of water in a double-blind, random order, cross-over fashion.

Sitting blood pressure and heart rate recordings were taken for 30 minutes preprandially and at 15 minute intervals for 90 minutes after completion of the meal and coffee drink. Erect blood pressure and heart rate recordings were taken immediately before the meal and every 30 minutes postprandially. Throughout the study subjects were questioned about the development of any new symptoms.

\section{Statistics}

All results are expressed as a mean \pm one standard error in the mean and $95 \%$ confidence intervals (CI) are also given where indicated. The differences between heart rate and blood pressure responses after each test were analysed by calculating the area under the curve (AUC) for that parameter by the trapezoid method giving an overall summary statistic for each subject for the whole study period for that meal and were compared by the paired Wilcoxon signed rank sum test. Baseline and maximum changes were compared by Student's $t$ tests.

\section{Results}

All subjects consumed the glucose and coffee drinks on each occasion and no adverse symptoms were reported. Preprandially there was no difference in sitting and erect systolic (SBP), diastolic blood pressure (DBP) or heart rate (HR) in either phase of the study (Table I).

The sitting blood pressure and HR changes over the study period are shown in Figure 1. Overall there was a significant difference in the change in sitting SBP between placebo and caffeine phases of the study $(P<0.05)$. After placebo there was an overall decrease in supine SBP of $-8 \mathrm{mmHg}(95 \%$ confidence interval -10 to $-6 \mathrm{mmHg}, P<0.01$ ) compared with an increase after caffeine of $+2 \mathrm{mmHg}$ (0 to $+4 \mathrm{mmHg}$, NS). There was no difference in the changes in DBP between placebog and caffeine, and overall there was a non-signis ficant decrease in DBP after placebo of $-6 \mathrm{mmH}$ $(-8$ to $-3 \mathrm{mmHg})$ and caffeine of $-1 \mathrm{mmHg}(-3$ to $-1 \mathrm{mmHg}$ ). There was no overall difference in changes in HR between placebo and caffeine Overall there was a small increase after both phases of the study of +5 beats per minute $(+3$ to +7 beats per minute, $P<0.05$ ).

Erect SBP, DBP and HR after placebo and caffeine are shown in Figure 2. There was no difference in changes in erect SBP between placebo and caffeine phases of the study postprandially. After placebo there was an overall decrease in erect SBP of $-6 \mathrm{mmHg}(-9$ to $-3 \mathrm{mmHg}, P<0.05)$ and after caffeine there was a non-significant

Table I Baseline sitting and erect systolic blood pressure (SBP), diastolic blood pressure (DBP) and heart rate (HR) for placebo and caffeine treatment phases. Values are means \pm s.e.m.

\begin{tabular}{lrr}
\hline & Placebo & Caffeine \\
\hline Sitting & & \\
SBP (mmHg) & $135 \pm 6$ & $133 \pm 6$ \\
DBP (mmHg) & $68 \pm 4$ & $70 \pm 4$ \\
HR (beats/min) & $75 \pm 3$ & $72 \pm 3$ \\
Erect & & \\
SBP (mmHg) & $133 \pm 6$ & $130 \pm 6$ \\
DBP (mmHg) & $70 \pm 4$ & $72 \pm 3$ \\
HR (beats/min) & $80 \pm 4$ & $79 \pm 3$ \\
\hline
\end{tabular}


Meal

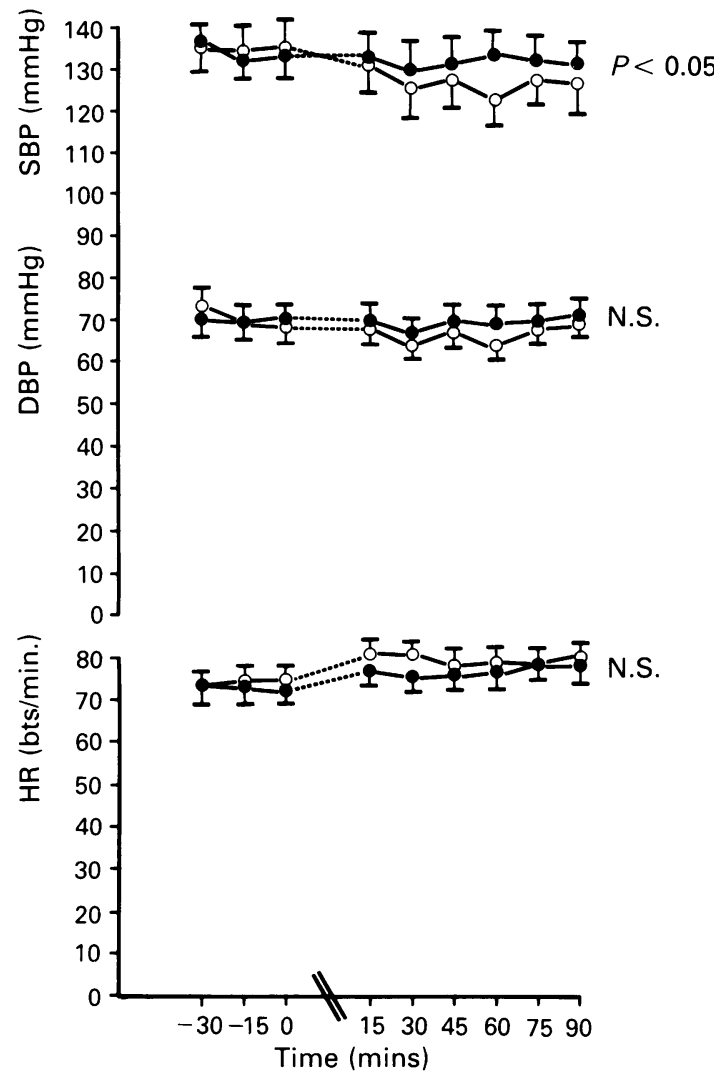

Figure 1 Changes in sitting systolic blood pressure (SBP), diastolic blood pressure (DBP) and heart rate (HR) during the 30-minute run in period and for 90 minutes after the carbohydrate drink with placebo $(\mathrm{O}-\mathrm{O})$ and caffeine $(\mathrm{O}-\mathrm{O})$. Values are means \pm 1 s.e.m. for 20 subjects.

decrease of $-5 \mathrm{mmHg}(-7$ to $-2 \mathrm{mmHg}$ ). There was no overall difference in erect DBP between treatment phases with no significant changes after placebo $-2 \mathrm{mmHg}(-4$ to $-1 \mathrm{mmHg})$ and caffeine of $0 \mathrm{mmHg}(-2$ to $+1 \mathrm{mmHg})$. Likewise, there was no overall difference in change in HR between placebo and caffeine; small increases occurred, after placebo of +5 beats per minute $(+3$ to $+7 \mathrm{mmHg}, P<0.05)$ and after caffeine of +3 beats per minute $(+2$ to +5 beats per minute, $P<0.05)$.

Maximum changes in sitting and erect SBP, DBP and HR after placebo and caffeine treatment phases are shown in Table II. Maximum reductions in sitting SBP occurred at 60 minutes postprandially after placebo of $-11 \mathrm{mmHg}(-17$ to $-6 \mathrm{mmHg}, P<0.01$ ), whereas at 60 minutes after caffeine there was a change in SBP of $+2 \mathrm{mmHg}$

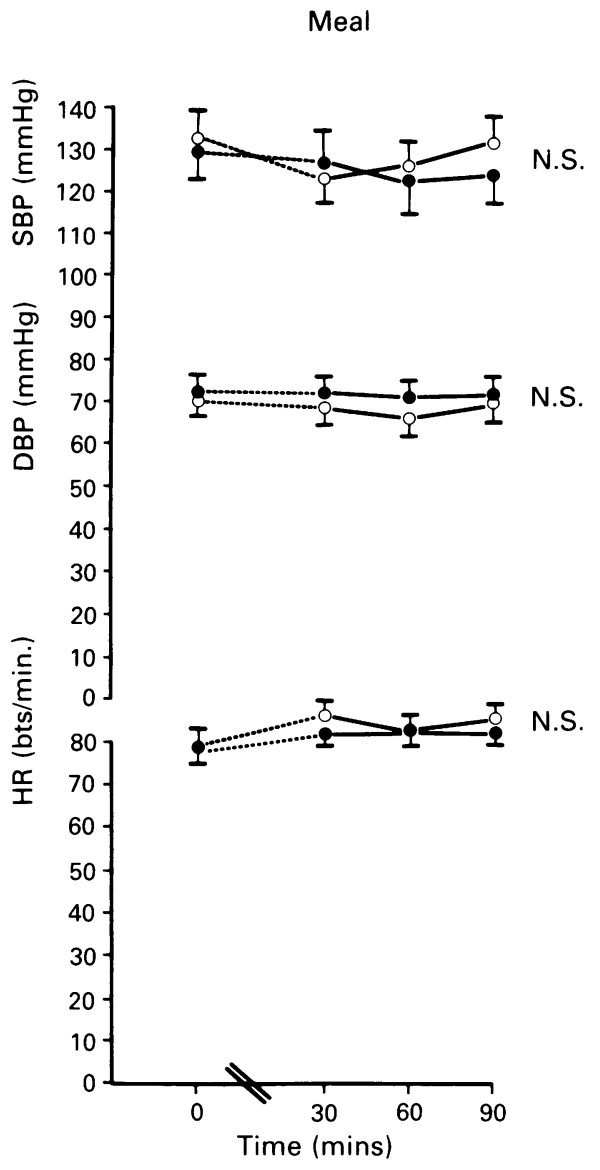

Figure 2 Changes in erect SBP, DBP and HR after the carbohydrate drink for placebo $(\mathrm{O}-\mathrm{O})$ and caffeine (-) (mean \pm 1 s.e.m.)

( -6 to $+7 \mathrm{mmHg}$, NS). Four subjects described symptoms of lethargy, tiredness and light-headedness after placebo, but not caffeine. In each subject sitting SBP fell to under $100 \mathrm{mmHg}$ with maximum changes of $-32 v s-26,-32 v s-10,-28 v s-14$, $-16 \mathrm{vs}-8 \mathrm{mmHg}$ after placebo and caffeine, respectively.

Postural changes in SBP, DBP and HR are shown in Table III. There was no overall difference in the change in sitting to erect SBP between placebo and caffeine phases of the study, although in the first 30 minutes after food there was an increase in the postural change in SBP of $-1 \pm 2$ to $-4 \pm 2 \mathrm{mmHg}$ after placebo compared to a decrease from $-4 \pm 2$ to $0 \pm 2 \mathrm{mmHg}$ after caffeine $(P<0.01)$. This difference was mainly due to changes in two subjects who developed symptomatic postural hypotension after placebo, but not 
Table II Maximum postprandial changes in sitting and erect SBP, DBP and HR after placebo and caffeine. Values are means \pm s.e.m.

\begin{tabular}{lcc}
\hline & Placebo & Caffeine \\
\hline Sitting & & \\
SBP (mmHg) & $-11 \pm 3$ & $+2 \pm 3^{*}$ \\
DBP (mmHg) & $-4 \pm 2$ & $-2 \pm 2$ \\
HR (beats/min) & $+5 \pm 2$ & $+7 \pm 2$ \\
Erect & & \\
SBP (mmHg) & $-10 \pm 3$ & $-8 \pm 4$ \\
DBP (mmHg) & $-4 \pm 3$ & $-1 \pm 3$ \\
HR (beats/min) & $+6 \pm 3$ & $+3 \pm 3$ \\
\hline
\end{tabular}

${ }^{*} P<0.01$ between placebo and caffeine.

Table III Postural changes in systolic blood pressure (SBP), diastolic blood pressure (DBP) and heart rate (HR) from sitting to erect position postprandially with placebo and caffeine (means \pm 1 s.e.m.)

\begin{tabular}{lrrrr}
\hline & Basal & 30 min & 60 min & 90 min \\
\hline SBP (mmHg) & & & & \\
$\quad$ Placebo & $-1 \pm 2$ & $-4 \pm 4$ & $-3 \pm 3$ & $1 \pm 2$ \\
$\quad$ Caffeine & $-4 \pm 2$ & $0 \pm 2$ & $-4 \pm 2$ & $-2 \pm 2$ \\
DBP (mmHg) & & & & \\
$\quad$ Placebo & $3 \pm 2$ & $6 \pm 2$ & $2 \pm 2$ & $0 \pm 2$ \\
$\quad$ Caffeine & $2 \pm 1$ & $6 \pm 2$ & $2 \pm 2$ & $1 \pm 2$ \\
HR (beats/min) & & & & \\
Placebo & $5 \pm 2$ & $6 \pm 2$ & $4 \pm 1$ & $7 \pm 2$ \\
Caffeine & $7 \pm 2$ & $7 \pm 2$ & $6 \pm 2$ & $5 \pm 1$ \\
\hline
\end{tabular}

caffeine (postural change in systolic SBP $>20$ $\mathrm{mmHg}$ ). One of these subjects had previously described symptoms of light-headedness and unsteadiness on standing. There were no overall differences in the postural changes in DBP or HR between placebo and caffeine treatment phases.

\section{Discussion}

The results of this study confirm the previous observations of postprandial BP reductions without compensatory increase in heart rate in frail elderly subjects. ${ }^{4}$ Furthermore, the administration of $100 \mathrm{mg}$ of caffeine attenuated the fall in sitting, but not standing BP.

\section{References}

1. Westenend, M, Lenders, J.W.M. \& Thien, Th. The course of blood pressure after a meal; a difference between young and elderly subjects. J Hypertension 1985, 3: S417-S419.

2. Peitzman, S.J. \& Berger, S.R. Postprandial blood pressure decrease in well elderly persons. Arch Intern Med 1989, 149: 286-288.
Previous studies have shown that $200-250 \mathrm{mg}$ of caffeine prevents postprandial hypotension in subjects with autonomic failure ${ }^{8}$ and in normal healthy elderly. ${ }^{13}$ In this study we evaluated the clinical significance of postprandial reductions of blood pressure by studying the subjects most likely to develop adverse symptomatology; the very old and frail with poor mobility, multiple pathology and taking multiple medications. Subjects were given caffeine in a dosage equivalent to a strong drink of coffee thus offering a practical treatment for patients with symptomatic postprandial hypotension. Interestingly, four subjects in this study did develop symptomatic postprandial hypotension which was prevented by caffeine.

The postprandial fall in erect BP was similar to the changes in sitting BP. This result in frail elderly subjects supports the findings in the fit elderly of no significant postprandial changes in sitting to standing postural tolerance. ${ }^{2,16,17}$ Two subjects did develop symptomatic postural hypotension (SBP fall $>20 \mathrm{mmHg}$ on standing) after food. However, unlike Robinson et al. we did not observe large postprandial reductions in sitting BP in these two subjects. $^{17}$

Overall, caffeine did not produce a significant alteration in either erect BP or the postural BP response, but in the two subjects who developed postprandial postural hypotension these changes were prevented by caffeine. It is likely that the mechanisms of postprandial and postural decline in BP are different, ${ }^{18}$ but in many elderly there may be a combination of factors (illness, medication, meal and postural change) which may interact and produce syncope.

In summary, a lower dose of caffeine $(100 \mathrm{mg}$ equivalent to one strong cup of coffee or tea) attenuates the postprandial fall in sitting, but not standing BP in frail elderly subjects. In particular, caffeine prevented both symptoms and BP changes in all 4 subjects with postprandial hypotension and 2 subjects with postural hypotension. Future studies should be directed to investigate the effects of caffeine in these problem groups of patients.

\section{Acknowledgement}

Miss Julie Kemp for secretarial assistance.

3. Potter, J.F., Heseltine, D., MacDonald, I.A., Harltey, G. \& James, O.F.W. Effects of meal composition on the postprandial blood pressure, catecholamine and insulin changes in elderly subjects. Clin Sci 1989, 77: 265-272. 
4. Lipsitz, L.A., Nyquist, R.P., Wei, J.Y. \& Rowe, J.W. Postprandial reduction in blood pressure in the elderly. $N$ Engl J Med 1983, 309: 81-83.

5. Minaker, K.L., Rowe, J.W., Young, J.B., Sparrow, D., Pallota, J.A. \& Landsberg, L. Effects of age on insulin stimulation of sympathetic nervous system activity in a man. Metabolism 1982, 31: 1181-1184.

6. Granger, D.N., Valleau, J.D., Parker, R.E., Lane, R.S. \& Taylor, A.E. Effects of adenosine on intestinal haemodynamics, oxygen delivery, and capillary fluid exchange. $\mathrm{Am}$ J Physiol 1978, 235: H707-H709.

7. Izzo, J.L., Ghosal, A., Kwong, T., Freeman, R.B. \& Jacnike, J.R. Age and prior caffeine use after the cardiovascular and adreno-medullary response to oral caffeine. Am J Cardiol 1983, 52: 769-773.

8. Robertson, D., Frohlich, J.C. \& Carr, R.K. Effects of caffeine on plasma renin activity, catecholamines and blood pressure. N Engl J Med 1978, 298: 181-186.

9. Smits, P., Hoffman, H., Thien, Th., Houben, H. \& Van't Laar, A. Haemodynamic and humoral effects of coffee after beta 1 selective and non-selective beta blockade. Clin Pharmacol Ther 1983, 34: 153-158.

10. Fredholm, B.S. Are methylxanthine effects due to the antagonism of endogenous adenosine? Trends Pharmacol Sci 1980, 1: $129-132$.

11. Onrot, J., Goldberg, M.R., Biaggioni, I., Hollester, A.C., Kincaid, D. \& Robertson, D. Haemodynamic and humoral effects of caffeine in autonomic failure: therapeutic implications for postprandial hypotension. $N$ Engl J Med 1988, 313: 549-554.
12. Lenders, J.W.M., Morre, H.L.C., Smits, P. \& Thien, Th. The effects of caffeine on the postprandial fall of blood pressure in the elderly. Age Ageing 1988, 17: 236-240.

13. Heseltine, D., Dakkak, M., MacDonald, I.A., Woodhouse, K. \& Potter, J.W. Caffeine prevents postprandial hypotension in the elderly. J Am Geriatr Soc 1991, 39: 160-164.

14. Bunker, M.L. \& McWilliams, M. Caffeine content of common beverages. J Am Diet Assoc 1979, 74: 28.

15. Lipsitz, L.A. \& Fullerton, K.J. Postprandial blood pressure reduction in healthy elderly. $\mathrm{J} \mathrm{Am}$ Geriatr Soc 1986, 34: 267-270.

16. Fagan, T.C., Conrad, K.A., Mayshar, P.V., Mackie, M.J. \& Hagaman, R.M. Effects of age and meals on orthostatic blood pressure and heart rate responses. Clin Pharmacol Ther 1988, 43: 142 (abstract).

17. Robinson, B.J., Johnson, R.H., Lambie, D.G. \& Palmer, K.T. Autonomic responses to glucose ingestion in elderly subjects with orthostatic hypotension. Age Ageing 1985, 14: $168-173$.

18. Lipsitz, L.A., Pluchino, F.C., Wei, J.Y., Minaker, K.L. \& Rowe, J.W. Cardiovascular and norepinephrine response after meal consumption in elderly (older than 75 years) persons with postprandial hypotension and syncope. $A m J$ Cardiol 1986, 58: 810-815. 